\title{
Perancangan Sistem Pemantau Ketinggian Sampah Menggunakan Mikrokontroler Arduino dan Aplikasi Berbasis Web
}

\author{
Eggi Chandra ${ }^{\# 1}$, Yus Sholva ${ }^{\# 2}$, Hafiz Muhardi ${ }^{\# 3}$ \\ \#Program Studi Informatika Fakultas Teknik Universitas Tanjungpura \\ Jl. Prof. Dr. H. Hadari Nawawi, Pontianak 78124 \\ ${ }^{1}$ bangeggsdegmail.com \\ ${ }^{2}$ sholvariza@untan.ac.id \\ ${ }^{3}$ hafizmeinformatika.untan.ac.id
}

\begin{abstract}
Abstrak- Sampah merupakan masalah perkotaan yang masih menjadi tantangan bagi pemerintah kota. Meningkatnya produksi sampah di daerah perkotaan, membuat pengelolaan sampah semakin kompleks. Dalam usaha pengelolaan sampah perkotaan, pemerintah Kota Pontianak menyediakan Tempat Pembuangan Sementara (TPS) di beberapa lokasi tertentu. Dalam usaha ini masih ditemukan kekurangan terkait pengontrolan tinggi timbulan sampah yang melebihi kapasitas kontainer sampah pada setiap TPS. Hal ini tentunya menyebabkan timbulan sampah yang meluap keluar dan menghasilkan pemandangan yang kurang baik serta pencemaran di lingkungan sekitar TPS. Untuk membantu permasalahan tersebut maka dibuat sebuah sistem yang mampu memantau ketinggian sampah dalam kontainer. Ketinggian sampah dijadikan parameter pengontrolan terhadap tinggi timbulan sampah, sehingga sebuah kontainer dikatakan belum penuh, hampir penuh dan penuh. Sistem yang dibangun bertugas memberikan informasi terkini mengenai tinggi timbulan sampah di dalam kontainer, untuk dijadikan data awal dalam menentukan kebijakan terkait pengelolaan sampah perkotaan, serta bisa menjadi data statistik terhadap aktivitas masyarakat dalam membuang sampah. Penelitian ini berhasil membangun sebuah prototipe sistem pemantauan ketinggian sampah menggunakan mikrokontroler Arduino dan aplikasi berbasis web. Mikrokontroler Arduino berfungsi untuk mengambil data ketinggian sampah, kemudian mengirimkannya ke server sehingga pengguna dapat memantau kondisi ketinggian sampah di dalam kontainer sampah melalui aplikasi website. Prototipe alat yang dibangun menggunakan Arduino Nano, Wemos D1 Mini, sensor jarak HC-SR04 dan LED (Light Emitting Diode). Pengujian yang dilakukan terhadap sistem terdiri dari pengujian hardware dan software. Berdasarkan hasil pengujian setiap sensor dapat menghitung jark atau ketinggian timbulan sampah yang terdapat dalam kontainer, serta menghitung rata-rata ketinggian hingga
\end{abstract}

disajikan dalam aplikasi website. Hasil baca sensor rata-rata menunjukan ada selisih sebesar $1 \mathrm{~cm}$ dibanding dengan pengukuran manual. Dari perbandingan nilai tersebut didapatlah nilai akurasi rata-rata $99 \%$ dan waktu rata-rata yang dibutuhkan sistem untuk upload data ke server adalah 6,5 detik. Secara keseluruhan dapat disimpulkan bahwa sistem dapat bekerja dengan baik.

Kata kunci - TPS, Arduino Nano, Wemos D1 Mini, Sensor Jarak, Kontainer Sampah, LED.

\section{PENDAhUluan}

Inovasi teknologi dan moderenisasi peralatan elektronik baik dari perangkat keras maupun perangkat lunak yang berkembang pesat sangat berguna untuk mendukung aktivitas manusia. Aktivitas penduduk yang tinggi dapat menyisakan permasalahan sosial yang cukup kompleks, terutama di bidang persampahan. Masalah persampahan menjadi sangat penting karena akan memberikan dampak dalam kehidupan masyarakat, mulai dari pencemaran lingkungan, banjir dan sampai pada sumber penyakit.

Penanganan sampah khususnya pada kota-kota besar di Indonesia merupakan salah satu permasalahan perkotaan yang masih menjadi tantangan bagi pengelola kota. Pertambahan penduduk dan peningkatan aktivitas yang demikian pesat di kota-kota besar, telah mengakibatkan meningkatnya jumlah sampah disertai permasalahannya [1]. Pengelolaan sampah pada masyarakat perkotaan bertambah lama bertambah kompleks sejalan dengan kekompleksan masyarakat itu sendiri. Dibutuhkan 
keterlibatan beragam teknologi dan beragam disiplin ilmu, dalam membantu pengelolaan sampah [1].

Menurut Kepala Dinas Lingkungan Hidup (DLH) Kota Pontianak, produksi sampah di Ibu Kota Provinsi Kalimantan Barat ini mencapai 350 - 400 ton per hari [2]. Hal ini tentunya berpotensi menciptakan masalah timbulan sampah yang melebihi kapasitas kontainer sampah di Tempat Penampungan Sementara (TPS). Melihat dari data sarana dan prasarana, DLH Kota Pontianak memiliki 110 TPS dengan jumlah kontainer sampah 103 buah, serta memiliki dump truck sebanyak 10 unit [3]. Dari perbandingan jumlah kontainer sampah yang cukup banyak dengan armada pengangkutan yang lebih sedikit, pihak DLH mengalami permasalahan dalam menciptakan lingkungan TPS yang bersih dan elok dipandang. Beberapa TPS terlihat kumuh akibat timbulan sampah yang meluap dari dalam kontainer sampai memasuki badan jalan sehingga menciptakan pencemaran udara disebabkan gasgas yang dihasilkan oleh sampah dan pencemaran tanah di sekitar TPS[2] .

Dalam melakukan pengelolaan sampah, Pemerintah Kota Pontianak yang dibantu oleh Dinas Lingkungan Hidup (DLH) telah melakukan beberapa upaya dalam menekan tingginya volume sampah dan lajunya pertumbuhan tumpukan sampah, salah satunya untuk mewujudkan ketertiban dalam pembuangan sampah ke TPS, maka diterbitkanlah Peraturan Daerah (PERDA) Nomor 6 Tahun 2006 tentang jadwal pembuangan sampah, dimana waktu yang diperbolehkan membuang sampah di TPS yakni mulai pukul 18.00 hingga 06.00 WIB. Kemudian dalam upaya menjaga kebersihan dan kerapian lingkungan TPS, pihak DLH juga memiliki perangkat Pengawas yang bertugas mengawasi dan mengontrol kondisi TPS yang dibantu oleh Pekerja Harian Lepas (PHL) dalam menjaga kebersihan dan kerapian di TPS, serta memastikan agar pengangkutan sampah ke Tempat Pembuangan Akhir (TPA) berjalan dengan maksimal. Akan tetapi tidak semua TPS bisa tertangani dengan baik, karena keterbatasan jumlah dari Pengawas dan PHL. Belum lagi dilapangan masih ditemukan pelanggaran terhadap PERDA yang dibuat, dimana pada waktu yang dilarang tetap terjadi pembuangan sampah di TPS [2].

Sebagai bagian dari masyarakat yang diharapkan peran sertanya untuk mendukung Pemerintah dalam menangani masalah sampah, maka muncul ide dari penulis untuk membangun sebuah sistem yang bisa membantu pihak terkait dalam memantau kondisi timbulan sampah pada bak atau kontainer sampah di setiap TPS dengan teknologi Internet of Thing (IoT). Yaitu sebuah prototipe sistem yang mampu mengukur ketinggian timbulan sampah secara otomatis dan melakukan pelaporan ketinggian sampah secara real time melalui jaringan internet [4]. Laporan ketinggian timbulan sampah pada kontainer di setiap TPS yang dihasilkan oleh sistem yang dibangun [5], akan menjadi sebuah informasi yang berguna bagi pihak pengelola dalam melakukan pengawasan dari jauh, selanjutnya akan membantu dalam mengambil kebijakan dan keputusan terkait upaya mengurangi tingkat kekumuhan di TPS. Dari informasi tersebut juga bisa menjadi data sains terkait prilaku masyarakat pada daerah tertentu dalam membuang sampah ke TPS.

\section{TINJAUAN PUSTAKA}

\section{A. Pengertian Sampah}

Pengertian dari sampah dapat ditemui dalam beberapa sudut pandang. Sampah merupakan produk samping dari aktivitas masyarakat dari hasil sisa produk atau sesuatu yang dihasilkan dari sisa-sisa penggunaan yang manfaatnya lebih kecil dari pada produk yang digunakan oleh penggunanya sehingga hasil dari sisa ini dibuang atau tidak digunakaan lagi [6]. Sementara referensi [7] menyebutkan bahwa "Sampah adalah sisa-sisa bahan yang telah mengalami perlakuan, baik karena diambil bagian utamanya atau karena pengolahan, dan sudah tidak bermanfaat, sedangkan bila ditinjau dari segi lingkungan dapat menyebabkan pencemaran atau gangguan kelestariannya".

Dalam undang-undang Nomor 18 tahun 2008 tentang pengolahan sampah pasal 1 mendefinisikan sampah sebagai sisa kegiatan sehari-hari manusia dan/atau proses alam berbentuk padat [8]. Sampah spesifik adalah sampah yang karena sifat, konsentrasi, dan/atau volumenya memerlukan pengelolaan khusus. Menurut definisi World Health Organization (WHO) sampah adalah sesuatu yang tidak digunakan, tidak dipakai, tidak disenangi atau sesuatu yang dibuang yang berasal dari kegiatan manusia dan tidak terjadi dengan sendirinya [6].

Tata Cara Teknik Operasional Pengelolaan Sampah Perkotaan, pengertian sampah perkotaan adalah limbah yang bersifat padat terdiri dari bahan organik dan bahan anorganik yang dianggap tidak berguna lagi dan harus dikelola agar tidak mambahayakan lingkungan dan melindungi investasi pembangunan yang timbul di kota [9].

Dari beberapa pendapat di atas dapat disimpulkan bahwa sampah adalah material dari sisa kegiatan manusia yang dibuang atau tidak digunakan lagi. Sampah yang dikelola di perkotaan adalah semua sampah yang timbul di kota baik sampah domestik maupun non domestik dan tidak termasuk sampah bahan berbahaya dan beracun (B3). Sampah bahan berbahaya dan beracun seperti sampah medis dan sampah industri, harus dilakukan penanganan khusus agar tidak membahayakan kualitas lingkungan.

\section{B. Komposisi dan Karakteristik Sampah}

Sampah dapat dikelompokan berdasarkan komposisinya, misalnya dinyatakan sebagai \% berat (biasanya berat basah) atau \% volume (basah) dari kertas, kayu, kulit, karet, plastik logam, kaca, kain, makanan, dan lain-lain [10]. Selain itu karakteristik lain yang biasa ditampilkan dalam penanganan sampah yaitu karakteristik fisika dan kimia sebagai berikut : 
1) Karakteristik fisika : yang paling penting adalah densitas, kadar air, kadar volatile, kadar abu, nilai kalor, dan distribusi ukuran.

2) Karakteristik kimia : khususnya yang menggambarkan sususnan kimia sampah yang terdiri dari unsur $\mathrm{C}, \mathrm{N}, \mathrm{O}, \mathrm{P}, \mathrm{H}, \mathrm{S}$, dan sebagainya.

Data mengenai karakteristik kimia sampah dapat dilakukan dengan cara analisa di laboratorium. Data ini erat kaitannya dengan komposisi fisiknya yang diperlukan dalam menentukan pertimbangan dalam memilih alternatif pegolahan sampah.

\section{Mikrokontroler}

Referensi [11] menyebutkan bahwa, "Mikrokontroler adalah sebuah chip yang di dalamnya terdapat mikroprosesor yang telah di kombinasikan I/O dan memori RAM/ROM". Mikrokontroler adalah suatu rangkaian terintegrasi (IC) yang bekerja untuk aplikasi pengendalian. Meskipun mempunyai bentuk lebih kecil dari komputer pribadi dan mainframe, mikrokontroler dibangun dengan elemen-elemen yang sama. Mikrokontroler adalah alat yang mengerjakan instruksi-instruksi yang diberikan, artinya bagian utama dari sistem otomatis / terkomputerisasi adalah program yang di dalamnya dibuat oleh programmer. Program menginstruksikan mikrokontroler untuk melakukan jalinan yang panjang dari aksi-aksi sederhana untuk melakukan tugas yang lebih kompoleks sesuai keinginan programmer [12].

Dari beberapa definisi yang disebutkan, dapat disimpulkan bahwa mikrokontroler adalah sebuah sistem fungsional dalam sebuah chip yang mempunyai prosesor, memori dan perlengkapan input dan output yang menjadi kendali dari sebuah program yang ditulis.

\section{Arduino Nano}

Arduino Nano merupakan suatu sistem minimum lengkap dengan ukuran yang relatif kecil berbasis mikrokontroler ATmega328 untuk Arduino Nano 3.x dan ATmega168 untuk Arduino Nano 2.x. Input dan Output, Arduino Nano memiliki jumlah pin sebanyak 14 pin yang dapat digunakan untuk input dan output dan memiliki beberapa fungsi pinMode(), digitalWrite(), digitalRead(). Pin Arduino Nano bekerja pada tegangan 5V dengan Arus 20mA serta memiliki tahanan pull - up $20-50 \mathrm{k}$ ohm. Arduino Nano memiliki beberapa fasilitas untuk komunikasi dengan komputer, Arduino lainnya maupun microcontroller lainnya. Atmega 328 menyediakan serial komunikasi UART TTL (5V), yang tersedia pada pin digital 0 (RX) dan 1 (TX) [13]. Board system minimum Arduino Nano dapat dilihat pada Gambar 1.

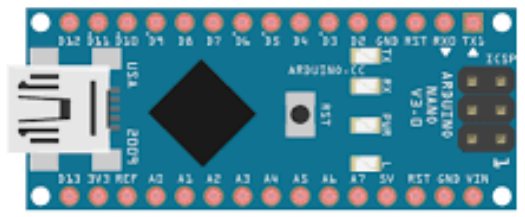

Gambar. 1 Arduino Nano

\section{E. Wemos D1 Mini}

Merupakan modul wifi yang berfungsi sebagai perangkat tambahan mikrokontroler seperti Arduino agar dapat terhubung secara langsung dengan jaringan wifi dan membuat koneksi TCP/IP. Modul ini membutuhkan daya sekitar 3.3V dengan memiliki tiga mode wifi yaitu Station, Access Point dan Both (keduanya). Modul ESP8266 juga dilengkapi dengan prosesor Tensilica's L106 Diamond series 32-bit, memori dan GPIO dimana jumlah pin bergantung dengan jenis ESP8266 yang digunakan. Modul ini bisa berdiri sendiri tanpa menggunakan mikrokontroler karena memiliki perlengkapan layaknya mikrokontroler. Modul Wemos D1 Mini memiliki 11 pin digital input/output, 1 analog pin input, clock speed $80 \mathrm{Mhz}$ dan flash 4 Mbytes [14],[15]. Gambar 2 merupakan contoh gambar Wemos D1 Mini.

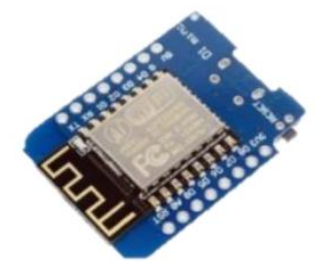

Gambar. 2 Wemos D1 Mini

\section{F. Sensor HC-SRO4}

HC-SR04 merupakan sensor ultrasonik yang dapat digunakan untuk mengukur jarak antara penghalang dan sensor. Konfigurasi pin dan tampilan sensor HC-SR04 diperlihatkan pada Gambar 3.

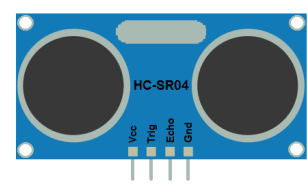

Gambar. 3 Sensor HC-SR04

HC-SR04 memiliki 2 komponen utama sebagai penyusunnya yaitu ultrasonic transmitter dan ultrasonic receiver. Fungsi dari ultrasonic transmitter adalah memancarkan gelombang ultrasonik dengan frekuensi 40 $\mathrm{KHz}$ kemudian ultrasonic receiver menangkap hasil pantulan gelombang ultrasonik yang mengenai suatu objek. Waktu tempuh gelombang ultrasonik dari pemancar hingga sampai ke penerima sebanding dengan 2 kali jarak antara sensor dan bidang pantul seperti yang diperlihatkan pada Gambar 4 [16].

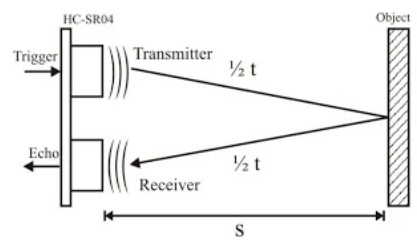

Gambar. 4 Prinsip kerja sensor HC-SR04 


\section{G. Ngrok}

Ngrok adalah sebuah program yang dibuat oleh Alan Shreve yang dapat menciptakan sebuah tunneling dari jaringan publik ke port komputer lokal menggunakan url yang diberikan oleh ngrok dengan format url : http://subdomain.ngrok.com. Ngrok akan membuat / membuka jaringan private melalui NAT atau firewall untuk menghubungkan localhost ke internet dengan tunnel yang aman. Cara kerja ngrok dapat dilihat pada Gambar 5 [17].

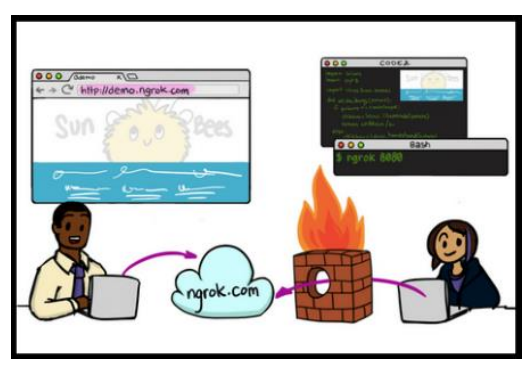

Gambar. 5 Konsep kerja ngrok

Dari Gambar. 5 menjelaskan bahwa ngrok adalah sebuah aplikasi yang digunakan untuk membuka server lokal dari NAT atau Firewall ke public network melalui tunnel yang aman. Dengan kata lain ngrok dapat menciptakan sebuah tunneling dari internet public ke port komputer lokal [18].

\section{Metode Penelitian dan PeRAnCANGAn Sistem}

\section{A. Arsitektur Sistem}

Desain arsitektur sistem akan ditunjukkan pada Gambar 6.

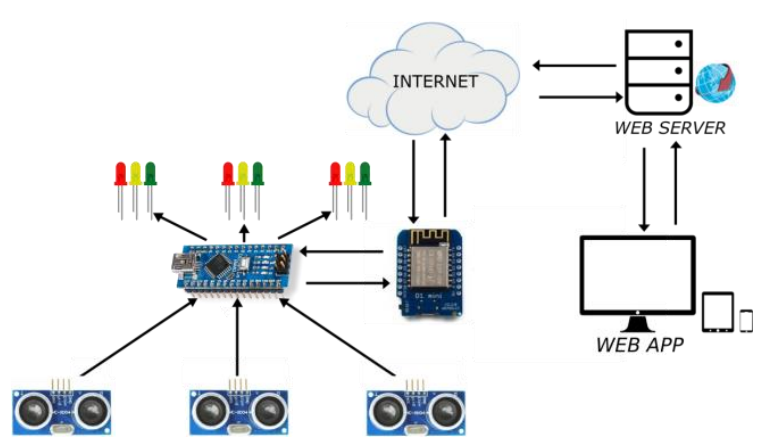

Gambar. 6 Arsitektur sistem

Pengguna bisa memantau kondisi kepenuhan sampah melalui peta persebaran kontainer dan pengguna yang berstatus sebagai admin dapat melakukan manajemen kontainer, sensor, melihat detail hasil baca sensor, melihat grafik hasil baca sensor dan manajemen petugas.

\section{B. Use Case Diagram}

Use case diagram aplikasi diperlihatkan pada Gambar 7.

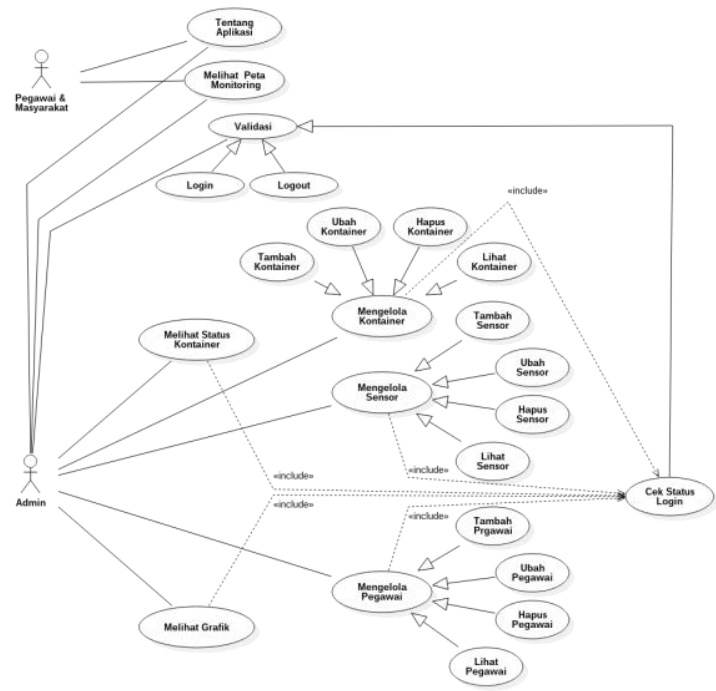

Gambar. 7 Use case diagram sistem

\section{Deployment Diagram}

Deployment diagram aplikasi diperlihatkan pada Gambar 8.

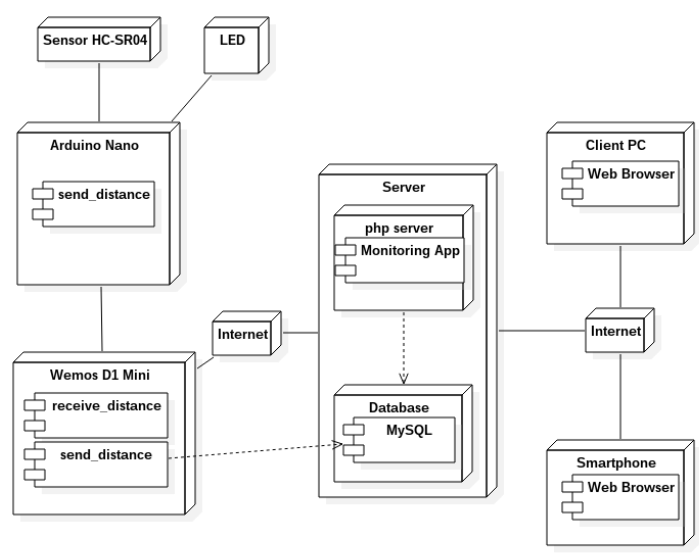

Gambar. 8 Deployment diagram sistem

\section{Pengujian Sistem}

Pengujian yang dilakukan meliputi pengujian hardware rangkaian mikrokontroler dan perngujian software aplikasi website. Pengujian software aplikasi website menggunakan metode Black Box. Dari berbagai metode pengujian di atas, penulis akan menganalisis hasil pengujian berupa keberhasilan sistem dalam melakukan tugas monitoring secara otomatis.

\section{HASIL IMPLEMENTASI PENGUJIAN}

\section{A. Rangkaian Mikrokontroler Sistem}

Hasil rangkaian pada mikrokontroler dapat dilihat pada Gambar 9. 


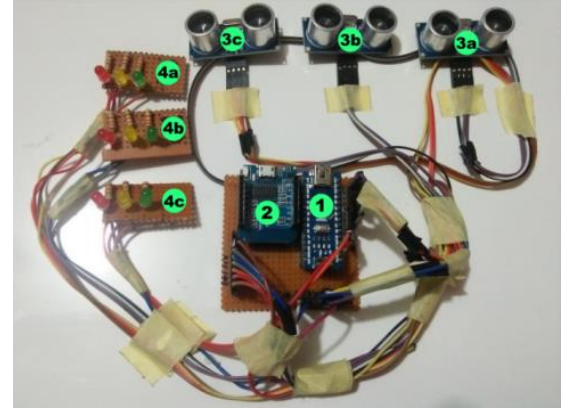

Gambar 9 Rangkaian mikrokontroler sistem

Gambar. 9 merupakan rangkaian mikrokontroler sistem yang terdiri dari Arduino Nano, Wemos D1 Mini, Sensor RC-SR04 dan LED warna yang telah dirangkai di atas papan PCB. Rangkaian mikrokontroler ini berfungsi sebagai alat pengukur ketinggian sampah pada sistem pemantau ketinggian sampah yang dibangun. Komponen pembangun rangkaian dapat dilihat pada Tabel 1 .

TABEL I

KOMPONEN PEMBANGUN RANGKAIAN MIKROKONTROLER

\begin{tabular}{|c|c|c|}
\hline \multirow{2}{*}{ Nomor } & Nama Komponen & Fungsional \\
\cline { 2 - 3 } $\mathbf{1}$ & Modul Arduino Nano & Sistem Kendali Utama \\
\hline $\mathbf{2}$ & Modul Wemos D1 Mini & Sistem Kendali Utama \\
\hline $\mathbf{3 a}$ & Sensor HC-SR04 -1 & Sensor Jarak \\
\hline \multirow{3}{3}{$\mathbf{b}$} & Sensor HC-SR04 -2 & Sensor Jarak \\
\hline \multirow{3}{*}{$\mathbf{4 a}$} & Sensor HC-SR04 -3 & Sensor Jarak \\
\cline { 2 - 3 } & LED -1 & Notifikasi \\
\hline \multirow{4}{*}{$\mathbf{4 b}$} & LED -2 & Notifikasi \\
\cline { 2 - 3 } & LED -3 & Notifikasi \\
\hline
\end{tabular}

Hasil implementasi rangkaian mikrokontroler sistem ke dalam prototipe kontainer sampah dapat dilihat pada Gambar 10.

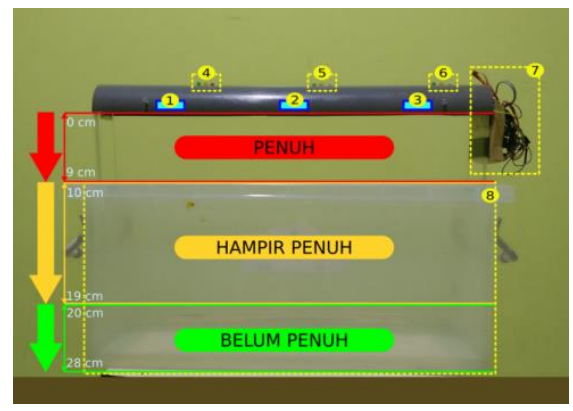

Gambar. 10 Prototipe hardware sistem monitoring ketinggian sampah

Pada Gambar 10, Rangkaian hardware sistem diimplementasikan ke box kontainer berbahan plastik dengan ukuran $47 \times 28 \times 19 \mathrm{~cm}$. Penjelasan dari prototipe hardware sistem dapat dilihat pada Tabel 2.

TABEL III

KOMPONEN-KOMPONEN PEMBANGUN PROTOTIPE HARDWARE SISTEM

\begin{tabular}{|c|c|c|}
\hline Nomor & Nama Komponen & Fungsional \\
\hline $\mathbf{1}$ & Sensor HC-SR04 -1 & Sensor Blok 01 \\
\hline $\mathbf{2}$ & Sensor HC-SR04 -2 & Sensor Blok 02 \\
\cline { 2 - 3 } $\mathbf{3}$ & Sensor HC-SR04 -3 & Sensor Blok 03 \\
\hline $\mathbf{4}$ & LED -1 & Notifikasi Blok 01 \\
\hline $\mathbf{5}$ & LED -2 & Notifikasi Blok 02 \\
\hline $\mathbf{6}$ & LED -3 & Notifikasi Blok 03 \\
\hline $\mathbf{7}$ & Rangkaian Alat Ukur & Sistem Kendali Utama \\
\cline { 2 - 3 } & Box Kontainer & Kontainer Sampah \\
\hline
\end{tabular}

\section{B. Antarmuka Aplikasi Website Pengguna Secara Umum}

Hasil rancangan antarmuka aplikasi website yang dibuat dapat dilihat pada Gambar 11.

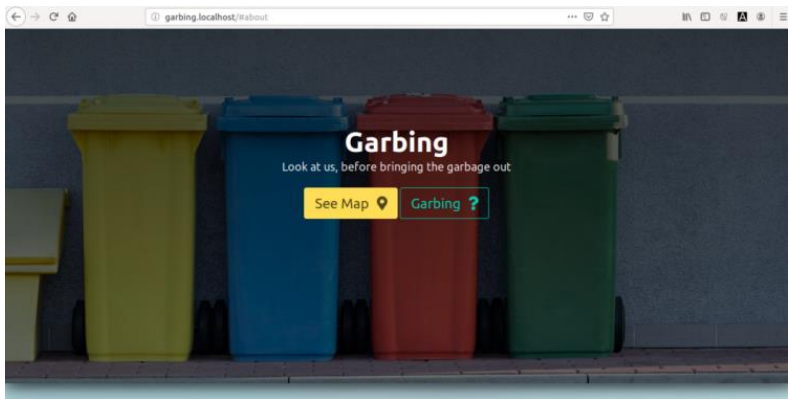

Gambar. 11 Antarmuka halaman utama website sistem

Gambar 11 merupakan tampilan Halaman Utama pada Aplikasi Website, halaman ini menampilkan peta persebaran kontainer sampah disertai keterangan tingkat kepenuhan sampahnya dan halaman tentang aplikasi. Keduanya diwakili dengan tombol See Map dan Garbing, jika mengklik tombol See Map, maka akan muncul halaman peta berikut.

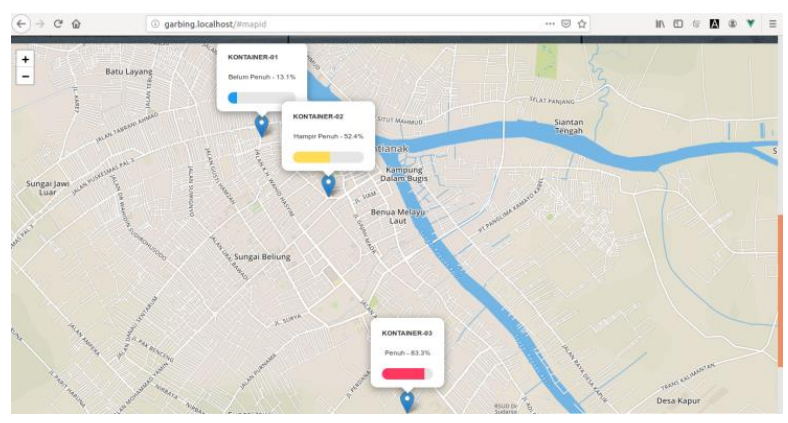

Gambar. 12 Antarmuka halaman peta monitoring

Gambar 12 adalah gambar halaman Peta Monitoring di Aplikasi Website. Melalui halaman ini, pengguna dapat 
melihat nilai ketinggian terakhir sampah pada kontainer sampah.

\section{Antarmuka Halaman Dashboard Admin}

Hasil rancangan antarmuka pada website admin sistem dapat dilihat pada Gambar 13.

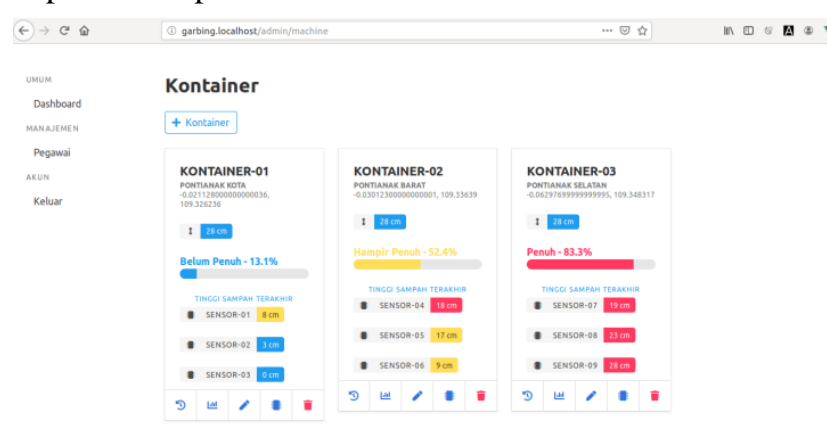

Gambar .13 Antarmuka halaman dashboard admin

Gambar 13 adalah gambar Halaman Dashboard Admin. Pada halaman ini, Pengguna yang berstatus admin dapat melihat nilai ketinggian timbulan sampah yang dipresentasikan sebagai nilai kepenuhan sampah dalam kontainer. Selain itu, Pengguna juga dapat melihat Grafik hasil baca sensor pada sebuah kontainer sampah.

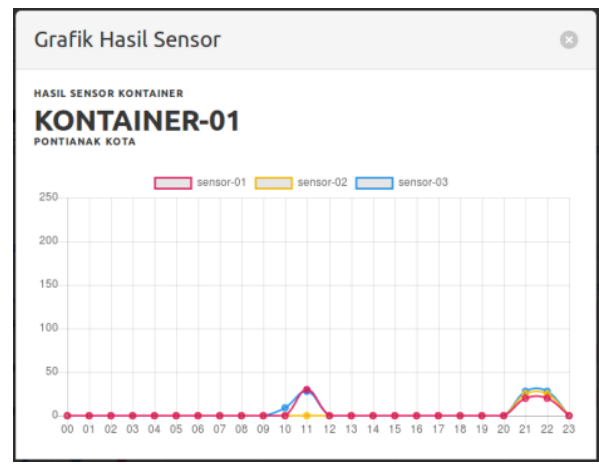

Gambar. 14 Grafik hasil baca sensor

Gambar. 14 merupakan tampilan grafik hasil baca sensor berupa nilai ketinggian timbulan sampah per jam. Garis Merah sensor1, Biru menandakan sensor 2 dan Kuning menandakan sensor 3 .

\section{Hasil Pengujian}

1) Pengujian Hardware Rangkaian Mikrokontroler: Pada Tabel 3, memperlihatkan hasil pengujian pada rangkaian mikrokontrole
TABEL IIIII

HASIL PENGUJIAN HARDWARE RANGKAIAN MIKROKONTROLER

\begin{tabular}{|c|c|c|c|c|}
\hline No & Pengujian & Test Case & $\begin{array}{c}\text { Hasil Yang } \\
\text { Diharapkan }\end{array}$ & $\begin{array}{c}\text { Hasil } \\
\text { Penguji } \\
\text { an }\end{array}$ \\
\hline 1 & $\begin{array}{l}\text { Arduino } \\
\text { Nano }\end{array}$ & $\begin{array}{l}\text { Upload sketch } \\
\text { program }\end{array}$ & Upload Done & Berhasil \\
\hline 2 & $\begin{array}{l}\text { Arduino } \\
\text { Nano }\end{array}$ & $\begin{array}{l}\text { Komunikasi } \\
\text { serial ke } \\
\text { Wemos D1 } \\
\text { Mini }\end{array}$ & $\begin{array}{l}\text { Kirim data } \\
\text { ketinggian ke } \\
\text { Wemos D1 Mini }\end{array}$ & Berhasil \\
\hline 3 & $\begin{array}{l}\text { Sensor HC- } \\
\text { SR04 }\end{array}$ & Scan jarak & $\begin{array}{l}\text { Dapat } \\
\text { menghitung } \\
\text { jarak }\end{array}$ & Berhasil \\
\hline 4 & LED & $\begin{array}{l}\text { Menyalakan } \\
\text { dan mematikan } \\
\text { LED dengan } \\
\text { Arduino Nano }\end{array}$ & $\begin{array}{l}\text { Dapat } \\
\text { menghidupkan } \\
\text { dan mematikan } \\
\text { secara otomatis }\end{array}$ & Berhasil \\
\hline 5 & $\begin{array}{l}\text { Wemos D1 } \\
\text { Mini }\end{array}$ & $\begin{array}{l}\text { Menghubungka } \\
\mathrm{n} \text { ke jaringan } \\
\text { wifi yang } \\
\text { ditentukan }\end{array}$ & $\begin{array}{l}\text { Terhubung ke } \\
\text { jaringan wifi }\end{array}$ & Berhasil \\
\hline 6 & $\begin{array}{l}\text { Wemos D1 } \\
\text { Mini }\end{array}$ & $\begin{array}{l}\text { Memperoleh } \\
\text { data sensor } \\
\text { dari Arduino }\end{array}$ & $\begin{array}{l}\text { Menampilkan } \\
\text { data sensor } \\
\text { sesuai dengan } \\
\text { data pada } \\
\text { Arduino }\end{array}$ & Berhasil \\
\hline 7 & $\begin{array}{l}\text { Wemos D1 } \\
\text { Mini }\end{array}$ & $\begin{array}{l}\text { Upload data } \\
\text { hasil sensor ke } \\
\text { server }\end{array}$ & $\begin{array}{l}\text { Data masuk ke } \\
\text { database server }\end{array}$ & Berhasil \\
\hline
\end{tabular}

2) Pengujian Sensor HC-SR04: Sebagai Pengukur Ketinggian Sampah.

Pada Tabel 4, memperlihatkan hasil pengujian pada sensor HC-SR04 dengan tiga kondisi, yaitu dengan permukaan datar (flat), permukaan dengan garis kontur (contur) dan permukaan acak (radom).

\section{TABEL IVV}

HASIL PENGUJIAN SENSOR ULTRASONIK DENGAN PERMUKAAN DATAR PADA PROTOTIPE KONTAINER SAMPAH

\begin{tabular}{|c|c|c|c|c|c|c|c|c|}
\hline \multicolumn{3}{|c|}{ Sensor 1} & \multicolumn{3}{|c|}{ Sensor 2} & \multicolumn{3}{|c|}{ Sensor 3} \\
\hline & & $\%$ & & & $\%$ & & & $\%$ \\
\hline Jarak & Jarak & Akur & Jarak & Jarak & Akur & Jarak & Jarak & Akur \\
\hline yang & yang & asi & yang & yang & asi & yang & yang & asi \\
\hline diuk & teruk & $(100$ & diuk & teruk & $(100$ & diuk & teruk & $(100$ \\
\hline ur & ur & $\%-$ & ur & ur & $\%-$ & ur & ur & $\%-$ \\
\hline $\operatorname{man}$ & sens & selisi & $\operatorname{man}$ & sens & selisi & $\operatorname{man}$ & sens & selisi \\
\hline ual & or & $\mathrm{h}$ & ual & or & $\mathrm{h}$ & ual & or & $\mathrm{h}$ \\
\hline$(\mathrm{cm})$ & $(\mathrm{cm})$ & $* 100$ & $(\mathrm{~cm})$ & $(\mathrm{cm})$ & $* 100$ & $(\mathrm{~cm})$ & $(\mathrm{cm})$ & $* 100$ \\
\hline & & $\%))$ & & & $\%))$ & & & $\%))$ \\
\hline 29 & 27 & 98 & 29 & 27 & 98 & 29 & 27 & 98 \\
\hline 11 & 11 & 100 & 11 & 11 & 100 & 11 & 11 & 100 \\
\hline 10 & 9 & 99 & 10 & 9 & 99 & 10 & 9 & 99 \\
\hline \multicolumn{2}{|c|}{$\begin{array}{c}\text { Rata-rata } \\
\text { akurasi }\end{array}$} & $\begin{array}{c}99,0 \\
0\end{array}$ & \multicolumn{2}{|c|}{$\begin{array}{c}\text { Rata-rata } \\
\text { akurasi }\end{array}$} & $\begin{array}{c}99,0 \\
0\end{array}$ & \multicolumn{2}{|c|}{$\begin{array}{c}\text { Rata-rata } \\
\text { akurasi }\end{array}$} & $\begin{array}{c}99,0 \\
0\end{array}$ \\
\hline
\end{tabular}

Dari Tabel 4, pengukuran jarak ketinggian sampah dilakukan dengan dua cara yaitu secara manual menggunakan alat ukur dan secara otomatis menggunakan sensor. Kedua hasil tersebut dibandingkan dan didapatlah persentasi rata-rata akurasi pengukuran senilai $99 \%$. 
TABEL V

Hasil PENGUJIAN SENSOR UltRASONIK DENGAN PERMUKAAN KONTUR PADA KEDUA KONTAINER

\begin{tabular}{|c|c|c|c|c|c|c|}
\hline \multirow{2}{*}{ Kontainer } & \multicolumn{2}{|c|}{$\begin{array}{c}\text { Ukuran Manual } \\
\text { Bidang Kontur } \\
(\mathbf{c m})\end{array}$} & \multicolumn{3}{|c|}{$\begin{array}{c}\text { Jarak yang Diukur Sensor } \\
(\mathbf{c m})\end{array}$} \\
\cline { 2 - 6 } & $\begin{array}{c}\text { Lever } \\
\mathbf{1}\end{array}$ & $\begin{array}{c}\text { Level } \\
\mathbf{2}\end{array}$ & $\begin{array}{c}\text { Level } \\
\mathbf{3}\end{array}$ & Sensor 1 & Sensor 2 & Sensor 3 \\
\hline I & 6 & 12 & 23 & 5 & 11 & 22 \\
\hline II & 6 & 12 & 23 & 5 & 11 & 22 \\
\hline
\end{tabular}

Dari Tabel 5, didapatkan pula nilai perbandingan dari pengukuran secara manual dan otomatis seperti sebelumnya. Namun dikondisi ini sampah dikondisikan pada ketinggian tertentu pada setiap garis konturnya yang disebutkan pada tabel dengan level satu sampai dengan tiga. Hasil pengujian sensor ultrasonik dengan permukaan sampah acak pada kedua kontainer dapat dilihat pada Tabel 6.

TABEL VI

HASIL PENGUJIAN SENSOR UltRASONIK DENGAN PERMUKAAN SAMPAH ACAK PADA KEDUA KONTAINER

\begin{tabular}{|c|c|c|c|c|c|c|}
\hline \multirow{3}{*}{ Kontainer } & \multicolumn{3}{|c|}{ Hasil Ukur pada Setiap Blok Kontainer } \\
\cline { 2 - 7 } & \multicolumn{2}{|c|}{ Blok 1 } & \multicolumn{2}{c|}{ Blok 2 } & \multicolumn{2}{c|}{ Blok 3 } \\
\hline \multirow{3}{*}{ I } & Sensor 1 & Manual 1 & Sensor 2 & Manual 2 & Sensor 3 & Manual 3 \\
\cline { 2 - 7 } & 8 & 9 & 14 & 15 & 21 & 22 \\
\cline { 2 - 7 } & 11 & 12 & 5 & 6 & 25 & 26 \\
\cline { 2 - 7 } & 13 & 14 & 11 & 12 & 6 & 7 \\
\hline \multirow{3}{*}{ II } & Sensor 4 & Manual 4 & Sensor 5 & Manual 5 & Sensor 6 & Manual 6 \\
\cline { 2 - 7 } & 25 & 26 & 5 & 6 & 19 & 20 \\
\cline { 2 - 7 } & 8 & 9 & 15 & 16 & 20 & 21 \\
\cline { 2 - 7 } & 11 & 12 & 26 & 27 & 7 & 8 \\
\hline
\end{tabular}

3) Pengujian Wemos DI Mini Dalam Mengirim Data ke Database.

Pada Tabel VII, memperlihatkan hasil pengiriman data menggunakan Wemos D1 Mini ke Database.

Dari Tabel 7, dapat dilijat rata-rata waktu yang diperlukan dalam mengirim data adalah 6,5 detik.

4) Pengujian Black Box Testing: Pengujian Black Box Testing dilakukan pada proses input yaitu saat login melalui Aplikasi Website. Hasil pengujian Black Box Testing dapat dilihat pada Tabel 8.
TABEL VII

HASIl PENGUJIAN KIRIM DATA DARI WEMOS KE DATABASE

\begin{tabular}{|c|c|c|c|c|}
\hline $\begin{array}{c}\text { Pengriri } \\
\text { man ke- }\end{array}$ & $\begin{array}{c}\text { Berhasil } \\
\text { (Ya / } \\
\text { Tidak) }\end{array}$ & $\begin{array}{c}\text { Waktu pada } \\
\text { serial monitor }\end{array}$ & $\begin{array}{c}\text { Waktu pada } \\
\text { database } \\
\text { server }\end{array}$ & $\begin{array}{c}\text { Waktu } \\
\text { yang } \\
\text { dibutuhka } \\
\text { n (detik) }\end{array}$ \\
\hline 1 & Ya & $10: 12: 44$ & $10: 12: 47$ & 3 \\
\hline 2 & Ya & $10: 12: 58$ & $10: 12: 59$ & 1 \\
\hline 3 & Ya & $10: 13: 11$ & $10: 13: 21$ & 10 \\
\hline 4 & Ya & $10: 13: 23$ & $10: 13: 24$ & 1 \\
\hline 5 & Ya & $10: 13: 30$ & $10: 13: 46$ & 16 \\
\hline 6 & Ya & $10: 13: 36$ & $10: 13: 49$ & 12 \\
\hline 7 & Ya & $10: 14: 01$ & $10: 14: 11$ & 10 \\
\hline 8 & Ya & $10: 14: 13$ & $10: 14: 14$ & 1 \\
\hline 9 & Ya & $10: 14: 26$. & $10: 14: 36$ & 10 \\
\hline 10 & Ya & $10: 14: 38$ & $10: 14: 39$ & 1 \\
\hline & Rata-rata waktu yang dibutuhkan (detik) & $\mathbf{6 , 5}$ \\
\hline & & & & \\
\hline & & & & 10 \\
\hline
\end{tabular}

TABEL VIII

TABEL PENGUJIAN BLACK BOX TESTING

\begin{tabular}{|c|l|l|c|}
\hline $\begin{array}{c}\text { Kasus / } \\
\text { Diuji }\end{array}$ & \multicolumn{1}{|c|}{ Skenario Uji } & $\begin{array}{c}\text { Hasil Yang } \\
\text { Diharapkan }\end{array}$ & $\begin{array}{c}\text { Hasil } \\
\text { Pengujian }\end{array}$ \\
\hline & $\begin{array}{l}\text { Memasukan } \\
\text { username dan } \\
\text { Password dengan } \\
\text { benar }\end{array}$ & $\begin{array}{l}\text { Masuk ke } \\
\text { halaman } \\
\text { dashboard } \\
\text { Admin }\end{array}$ & Berhasil \\
\cline { 2 - 4 } Login & $\begin{array}{l}\text { Memasukan dan } \\
\text { Username dengan } \\
\text { Password desalifikasi } \\
\text { salah }\end{array}$ & $\begin{array}{l}\text { Muncul } \\
\text { kesalahan } \\
\text { input data }\end{array}$ \\
\hline
\end{tabular}

\section{PEMBAHASAN}

Dari pengujian yang sudah dilakukan, dapat disimpulkan bahwa, hasil pengujian software menunjukan aplikasi website yang dijalankan dengan mengakses url dari website tersebut melalui perangkat laptop dan smartphone dapat berjalan lancar. Tampilan pada setiap perangkat dapat berbeda. Hal ini disebabkan oleh perbedaan ukuran, resolusi layar, serta costum room atau costum display yang terdapat pada perangkat itu sendiri.

Waktu rata-rata yang dibutuhkan untuk upload data ke server adalah 6,5 detik, ini menunjukan bahwa waktu yang dibutuhkan masih bisa dianggap sebagai kondisi real time dari ketinggian timbulan sampah di dalam kontainer pada TPS. Data tersebut akan diolah oleh aplikasi website untuk kemudian ditampilkan pada antarmuka aplikasi untuk diakses oleh pengguna.

Semakin sedikit jeda waktu antara pengambilan data dari sensor sampai upload data ke server maka akan semakin baik karena datanya akan bersifat real time. 
Rangkaian mikrokontroler rata-rata membutuhkan waktu 25 detik untuk bekerja stabil, jeda waktu yang terjadi dipengaruhi oleh koneksi internet pada perangkat pengguna dan kestabilan server sistem.

\section{KESIMPULAN}

Berdasarkan hasil analisis dan pengujian terhadap sistem pemantauan ketinggian sampah menggunakan mikrokontroler arduino dan aplikasi berbasis web, dapat disimpulkan bahwa:

1. Sistem yang dirancang dapat memantau ketinggian sampah dengan menggunakan sensor HC-SR04 yang digunakan sebagai pengukur ketinggian timbulan sampah yang dibuktikan dengan nilai jarak antara sensor dengan objek sampah yang berubah-ubah sesuai dengan kondisi tinggi timbulan sampah di dalam kontainer sampah pada saat pengujian.

2. Sistem dapat mengirim data hasil monitoring tinggi timbulan sampah ke server melalui jaringan internet. Mikrokontroler Arduino Nano yang bertindak sebagai kendali utama, mendapatkan nilai ketinggian sampah dari sensor, lalu dikirim ke server melalui perantara Wemos D1 Mini yang terhubung dengan jaringan internet.

3. Perbandingan antara pengukuran manual dengan pengukuran menggunakan sensor, rata-rata mendapatkan nilai akurasi yang sama, yaitu hasil pengukuran sensor memiliki selisih $1 \mathrm{~cm}$ dari nilai hasil pengukuran manual yang menunjukan tingkat akurasi $99 \%$.

4. Secara keseluruhan dapat disimpulkan bahwa prototipe sistem yang dibangun bisa melakukan tugas monitoring terhadap ketinggian sampah dan kemudian disajikan dalam bentuk informasi visual tentang tingkat kepenuhan sampah pada setiap kontainer yang terdata oleh sistem, kemudian disajikan ke aplikasi website yang dibangun dan informasi tersebut bisa diakses oleh masyarakat sebelum melakukan aktivitas pembuangan sampah ke TPS. Adapun bagi pihak pengelola bisa melakukan control dari jarak jauh terkait tinggi timbulan sampah agar tidak melebihi tinggi kontainer, yang menjadi sebab pencemaran lingkungan di sekitar TPS dan berakibat terhadap terciptanya pemandangan yang tidak elok bagi masyarakat sekitar TPS tersebut.

\section{REFERENSI}

[1] E. Damanhuri, "Teknologi dan pengelolaan sampah kota di indonesia," Work. Nas. Biokonvers. Limbah Univ. Brawijaya Malang, no. April, pp. 1-11, 2006.

[2] T. Butar Butar, "Proses bisnis pengelolaan persampahan Kota Pontianak." Dinas Lingkungan Hidup Pontianak, 2019.

[3] Pemerintah Kota Pontianak, Profil Dinas Lingkungan Hidup Kota Pontianak Tahun 2017. Pontianak, 2017.

[4] IUCN, "Ichwan, M., Husada, M. G., \& Rasyid, M. I. A. (2013). Pembangunan prototipe sistem pengendalian peralatan listrik pada platform android. Jurnal Informatika, 4(1), 13-25.," Pembang. Prototipe Sist. Pengendali. Peralat. List. Pada Platf. Android, vol 4, no. Ichwan, M., Husada, M. G., Rasyid, M. I. A. (2013).
Pembangunan prototipe sistem pengendalian peralatan listrik pada platform android. Jurnal Informatika, 4(1), 13-25., pp. 13-25, 2006.

[5] M. A, A. nogroho Jati, and U. ali Ahmad, "Perancangan Dan Implementasi Sistem Monitoring Untuk Pelaporan Sampah Berbasis Teknologi Embedded Design and Implementation Monitoring System for Reporting Waste Based Embedded Technology," e-Proceeding Eng., vol. 3, no. 1, pp. 666-673, 2016.

[6] E. Widawati, H. Tanudjaja, I. Iskandar, and C. Budiono, "Kajian Potensi Pengolahan Sampah (Studi Kasus: Kampung Banjarsari)," J. Metris, vol. 15, pp. 119-126, 2014.

[7] T. A. Ramandhani, "Analisis Timbulan dan Komposisi Sampah Rumah Tangga di Kelurahan Mekar Jaya (Depok) Dihubungkan dengan Tingkat Pendapatan-Pendidikan-Pengetahuan-SikapPerilaku Masyarakat,” p. Tugas Akhir. Fakultas Teknik. Program Studi Teknik, 2011.

[8] Pemerintah Indonesia, Undang-undang Republik Indonesia Nomor 18 tahun 2008 tentang Pengelolaan Sampah. Jakarta: Menteri Hukum dan Hak Asasi Manusia., 2008.

[9] Standar Nasional Indonesia, "SNI 19-2454-2002 Tata Cara Teknik Operasional Pengelolaan Sampah Perkotaan,” no. ICS 27.180, p. 1, 2010.

[10] E. Damanhuri and T. Padmi, Diktat kuliah TL-3104 Pengelolaan Sampah, 2010/2011. Bandung: ITB, 2010.

[11] J. Prayudha, D. Nofriansyah, and M. Ikhsan, "Otomatisasi pendeteksi jarak aman dan intensitas cahaya dalam menonton televisi dengan metode perbandingan diagonal layar berbasis mikrokontroler atmega 8535," Saintikom, vol. 13, no. 3, pp. 171184, 2014.

[12] H. L. Sadewa, H. Sujaini, and R. D. Nyoto, "Implementasi Mikrokontroler Pada Sistem Kontrol Peralatan Listrik dan Monitoring Rumah Berbasis Website," J. Edukasi dan Penelit. Inform., vol. 1, no. 2, 2015.

[13] Arduino, "Arduino Nano," 2018. [Online]. Available: https://store.arduino.cc/usa/arduino-nano.

[14] S. K. Dewi, R. D. Nyoto, and E. D. Marindani, "Perancangan Prototipe Sistem Kontrol Suhu dan Kelembaban pada Gedung Walet dengan Mikrokontroler Berbasis Mobile," J. Edukasi dan Penelit. Inform., vol. 4, no. 1, p. 36, 2018.

[15] P. R. Hanif, T. Tursina, and M. A. Irwansyah, "Prototipe Jam Sholat Qomatron Dengan Konsep Internet of Things (IoT) Menggunakan Wemos D1 Mini Berbasis Web," J. Sist. dan Teknol. Inf., vol. 6, no. 3, p. 117, 2018.

[16] Elec Freaks, "HC SR04 Ultrasonic Ranging Sensor Module," 2014 [Online]. Available: https://www.pcbway.com/blog/News/New_product_in_gift_shop_ _HC_SR04_Ultrasonic_Ranging_Sensor_Module.html.

[17] A. Shreve, "What is ngrok?," 2019. [Online]. Available: https://ngrok.com/product.

[18] Soeleman, "Ngrok," 2018. [Online]. Available: https://www.codepolitan.com/ngrok-5b289135af2f1. 